\title{
MAIS DO QUE DINHEIRO: PINK MONEY E A CIRCULAÇÃO DE SENTIDOS NA COMUNIDADE LGBT+
}

\author{
More than money: pink money and the circulation of \\ senses in the LGBT+ community
}

\author{
Más que dinero: pink money y la circulación de sentidos \\ en la comunidad LGBT+
}

\author{
Arize Souza Fernandes de Oliveira \\ Universidade Federal do Rio de Janeiro \\ Mestre pelo Programa de Pós-Graduação em Psicossociologia de Comunidades e Ecologia Social, \\ do Instituto de Psicologia da Universidade Federal do Rio de Janeiro (IP/UFRJ). \\ E-mail: arizefernandes@gmail.com
}

\author{
Mônica Machado \\ Universidade Federal do Rio de Janeiro \\ Professora Associada da UFRJ. Doutora em Comunicação e Cultura na Escola de Comunicação \\ da UFRJ e Mestre em Multimeios pela Universidade Estadual de Campinas (Unicamp). \\ E-mail: monica.machado@eco.ufrj.br
}

RESUMO: Diante da crescente investida das marcas em campanhas publicitárias de apoio à diversidade de orientação sexual e de gênero, o presente artigo busca apontar alguns argumentos da comunidade LGBT+ a respeito do tema. Os discursos foram analisados a partir da observação participante de eventos realizados no Rio de Janeiro em 2019. As principais reflexões relevam que, para além da visibilidade auferida pelas iniciativas das marcas, as discussões circulantes demonstram especial preocupação dos participantes com os afetos dos indivíduos representados pelas campanhas e com seu impacto nas relações socioeconômicas.

PALAVRAS-CHAVE: Pink money, Comunidade LGBT+, Observação participante.

ABSTRACT: Considering the growing onslaught of brands in advertising campaigns to support the diversity of sexual orientation and gender, this article points out some arguments from the LGBT+ community regarding the theme. The speeches were analyzed based on the participant observation of events held in Rio de Janeiro, in 2019. The main reflections show that far beyond the visibility gained by the initiatives of the brands, the circulating discussions show special concern with the affections of the individuals represented by such campaigns and how their socio-economic relations can be affected.

KEYWORDS Pink money, LGBT+ community, Participant observation

RESUMEN: En vista de la creciente circulación de marcas en campañas publicitarias para apoyar la diversidad de orientación sexual y de género, este artículo propone señalar algunos argumentos de la comunidad LGBT+ con respecto al tema. Los discursos se analizaron a partir de la observación participante de eventos en Río de Janeiro en 2019. Las principales reflexiones muestran que, mucho más allá de la visibilidad obtenida por las iniciativas de las marcas, las discusiones circulantes muestran una especial preocupación, por parte de los participantes, por el afecto de las personas representadas por tales campañas y cómo pueden verse afectadas sus relaciones socioeconómicas.

PALABRAS-CLAVE: Pink money, Comunidad LGBT +, Observación participante.

\section{Como citar este artigo:}

OLIVEIRA, A. S. F.; MACHADO, M. Mais do que dinheiro: pink money e a circulação de sentidos na comunidade LGBT+. Signos do Consumo, São Paulo, v. 13, n. 1, p. 20-31, jan./jun. 2021. 


\section{INTRODUÇÃO}

Há notório crescimento em nosso país de empresas que investem em campanhas publicitárias de apoio à diversidade de orientação sexual e de gênero. Prova disso é o volume de signatárias no Fórum de Empresas e Direitos LGBTI+, organização que reúne instituições em torno da promoção dos direitos $\mathrm{LGBT}+{ }^{1}$ e tem como objetivo influenciar tanto o meio empresarial como a sociedade sobre a temática (SALES, 2017). O fórum surgiu em 2013 com um pequeno grupo de instituições participantes e hoje já soma quase 100 empresas apoiadoras ${ }^{2}$ de diferentes setores e com alta relevância no mercado, como Itaú, Ambev e Vivo.

Diante de tamanha aproximação do mercado com a causa, surgem alguns questionamentos: são legítimas as campanhas que usam dessa bandeira? As iniciativas são positivas? Há vieses oportunistas nesses discursos? O que se ganha e o que se perde na apropriação da temática LGBT+ pelo mercado?

Longe de dar respostas a todos esses questionamentos, a proposta deste artigo é delinear alguns dos argumentos observados em encontros da comunidade LGBT+ a respeito dessa relação comercial. Este estudo usa como base os dados levantados durante o trabalho de campo da pesquisa de dissertação de uma das autoras ${ }^{3}$ (OLIVEIRA, 2020). O estudo foi realizado com um grupo de pessoas participantes de uma organização não governamental (ONG) LGBT+ no Rio de Janeiro: a Casinha. O projeto, de inspiração etnográfica, foi realizado através de entrevistas, de análises das redes sociais e de observação participante. Na construção teóricometodológica e nas análises feitas, alguns conceitos procedentes de contextos e de tradições de pensamento diferentes se tornaram frutíferos para guiar a investigação. Para o presente artigo, foram selecionados como material de análise os dados obtidos em discursos observados em três diferentes eventos realizados na cidade do Rio de Janeiro durante o ano de 2019.

As principais reflexões revelam que, muito além da visibilidade auferida pelas campanhas e iniciativas das marcas, as discussões circulantes nos grupos acompanhados demonstram especial preocupação com os afetos dos indivíduos representados por tais campanhas e com o modo pelo qual suas relações socioeconômicas podem ser impactadas.

\section{DISCUSSÃO TEÓRICO-METODOLÓGICA}

\section{Discussão teórica: contexto da comunidade e o discurso publicitário}

O atual cenário da aceitação de sexualidades não normativas aponta para um cenário de ambiguidade de pontos de vistas. É possível considerar que somos "uma sociedade mais aberta, mais tolerante e mais

1. Optamos por usar o termo "lésbicas, gays, bissexuais, transexuais e demais designações" $(\mathrm{LGBT}+)$ por ser comumente utilizado, nos dias de hoje, para se referir às orientações sexuais diferentes da heterossexual e às orientações de gênero diferentes da cisgênera.

2. A lista completa está disponível no site da organização (FÓRUM DE EMPRESAS E DIREITOS LGBTI+, 2016). Disponível em: https://bit.ly/3wgh9c7. Acesso em: 30 jul. 2020.

3. A pesquisa obedeceu às exigências do Comitê de Ética em Pesquisa do Centro de Filosofia e Ciências Humanas (CEP-CFCH) da Universidade Federal do Rio de Janeiro (UFRJ) e o parecer positivo ( $n^{\circ} 3.408 .629$ ) pode ser consultado na Plataforma Brasil. 
sensual” (SPARGO, 2017, p. 10), seja pela recorrência da temática LGBT+ na teledramaturgia, seja pelos direitos conquistados, como o de casar ou o de adotar crianças e adolescentes. Entretanto, essa visão contrasta com a intolerância evidente nos números de assassinatos e denúncias de violência no Brasil. Em 2018, o número de assassinatos de LGBT chegou a 420, o que tornou o Brasil um dos países que mais registra crimes contra LGB no mundo (GRUPO GAY DA BAHIA, 2018). Por um lado, enquanto tempos mais amigáveis parecem despontar, por outro, a intolerância ainda se traduz em estatísticas alarmantes.

Há um crescimento dos movimentos conservadores em diversos países (BLEE; CREASAP, 2010), que se materializa na manutenção do preconceito. Em 2018, por exemplo, pela primeira vez, o relatório da Gay \& Lesbian Alliance Against Defamation (GLAAD) mostrou uma queda no índice de aceitação de pessoas $\mathrm{LGBT}+{ }^{4}$. Esse fato confirma a necessidade de ampliação do debate e da reflexão a respeito de temas sobre essa comunidade, pois a resistência à intolerância e ações educativas ainda são necessários para se combater a vulnerabilidade. Neste artigo, em específico, é lançado o olhar sobre o entrelaçamento dessas ações e resistências com as questões mercadológicas inerentes ao universo capitalista no qual a organização LGBT estudada está imersa.

As implicações mercadológicas à comunidade LGBT+ não é fenômeno novo. Esse ponto, inclusive, representa um papel importante na formação do grupo. Facchini e França (2009) afirmam que, a partir da segunda metade dos anos 1990, a postura de visibilidade alinhada à diversificação do então chamado mercado de gays, lésbicas e simpatizantes (GLS) contribuiu para se estabelecer a ideia do "orgulho gay". Passou-se a valorizar a "orgulho" e o assumir-se publicamente. Esse atravessamento com o mercado que abre espaço ou se dirige aos homossexuais como potenciais consumidores é um dos sinais característicos do movimento LGBT+ a partir dos anos 1990. Desde então, "tanto as agências estatais quanto o mercado segmentado têm contribuído para reforçar a adesão a um sistema classificatório moderno, imprescindível para que uma política de identidades LGBT se torne viável" (FACCHINI; FRANÇA, 2009, p. 65).

Nesse sentido, há duas vertentes possíveis para refletir sobre o consumo associado ao público LGBT+. Podem ser levados em consideração nos estudos os produtos, serviços e locais destinados especificamente para esse público, assim como as características do mercado direcionado para homossexuais (FRANÇA, 2012; NUNAN, 2003) Mas há também uma perspectiva mais expandida, que observa o modo pelo qual a causa da diversidade se faz presente no posicionamento da marca e não somente nos produtos específicos para o consumo. Dentro desse aspecto, diversas marcas têm desenvolvido iniciativas em apoio à causa. Nesse universo, os bens passam a funcionar como comunicadores de sentido (DOUGLAS; ISHERWOOD, 2004).

O controverso debate sobre as relações entre consumo, política e cidadania não é novo e está na base da discussão da tradição crítica da indústria cultural, como nas teses de Adorno e Horkheimer (1991) que sustentam corresponderem a racionalidade técnica, a disseminação da razão instrumental e a objetividade científica ao aprisionamento dos sistemas de pensamento em fórmulas, padrões e clichês. Nessa tradição,

4. A GLAAD é uma organização não-governamental estadunidense que monitora a maneira como a mídia retrata as pessoas LGBT. Seu relatório "Accelerating Acceptance 2018” (GLAAD, 2018) está disponível em: https://bit.ly/3wbs8DH. Acesso em: 30 jul. 2020. 
a publicidade está no centro da crítica, pois suas técnicas seriam, em tese, aglutinadoras da "falsa consciência”. Assim sendo, o campo publicitário passa a ser visto como promotor do pensamento unidimensional, como bem refletia Marcuse (1992). Na tradição sociossemiótica, os pressupostos de Baudrillard (1995) no seu estudo clássico A sociedade de consumo também dão o tom da narrativa: os templos de consumo são vistos como espaços construídos nas lógicas de representações publicitárias, nas quais a ideia de objetos simulacro domina as cenas das produções sígnicas. Em outra perspectiva alinhada à crítica da publicidade, Bauman (2008), em Vida para o consumo, argumenta que, na passagem da sociedade dos produtores para a de consumidores, investimos em um sistema cultural de valorização das relações transitórias e sem territórios de origem. Assim, os traços da modernidade líquida apareceriam na produção publicitária que valoriza vínculos de pertencimentos frágeis e superficiais.

Já na tradição dos estudos culturais britânicos, valiosas são as contribuições de Williams (1985) ao formular o conceito de materialismo cultural entre os meios de produção e as formações socioculturais. Na chave conceitual dessa corrente teórica, as produções culturais podem tanto reafirmar lógicas dominantes como também reagir como espaços de resistências. Assim, as leituras do campo cultural devem ser analisadas em suas singularidades. De igual valor são as contribuições de Hall (1986) nos debates sobre representações e identidades que circulam nos discursos midiáticos.

Como já desenvolvemos em outros estudos (MACHADO, 2011), nos interessa reter dessa tradição crítica a ideia de que é preciso desenvolver o recurso de análise dos planos de leituras dos discursos midiáticos, particularmente, das narrativas publicitárias, para investigar a validade das teses tanto sobre a reafirmação e repetição de lógicas de dominação, quanto sobre a produção de discursos contrahegemônicos, capazes de abrir algum espaço de reflexão crítica e de elaborar novas perspectivas de pensamento.

É importante destacar que, na retórica dominante do discurso publicitário contemporâneo, ao buscar interface com o mundo da política ou, mais detidamente, com as causas sociais, certas narrativas predominam. Os discursos de ativismos de marcas têm certos traços dominantes:

a) A apropriação do discurso político no universo de marcas está fortemente marcada por uma visão neoliberal, segundo a qual os sujeitos individuais são ativos nos processos de decisões de escolha. A liberdade de escolha é um dos valores cultuados nessa tradição. Tal perspectiva retira a força dos movimentos sociais de base - partidos, sindicatos e instituições de classe - como espaços de construção da ordem democrática, transmitindo a impressão de que, por meio do consumo, tudo se resolve, pois nele o sujeito é livre para escolher.

b) Já que são os sujeitos individuais os protagonistas nos discursos publicitários, a autorrealização é altamente sedutora, de modo que os processos de construção da política atravessam os sentidos simbólicos das subjetividades em uma ambientação de culto ao hedonismo. O prazer de ser livre é altamente explorado como uma proposição política.

c) A noção de cidadania se atrela ao conceito de autenticidade em muitos discursos publicitários. O "eu" autêntico aparece como projeto de subjetivação que absorve a luta pelo reconhecimento no campo social, como a noção de Taylor (1992) bem traduz, 
a promoção do discurso de autenticidade na retórica publicitária está identificada com códigos internos de regulação dos sujeitos sociais. Assim, as causas sociais são atravessadas por fortes marcações das subjetividades em jogo no discurso promovido por marcas.

É nesse sentido que marcas prometem um discurso de engajamento e cidadania. Repertórios esses que, muitas vezes, são limitados em suas funções sociais, mas altamente sedutores como discursos de participação e de envolvimento em causas coletivas, haja vista o numeroso apoio para campanhas publicitárias que envolvem o tema. Para ilustrar, cabe citar um recente episódio envolvendo uma marca de cosméticos e sua escolha de um homem trans para sua campanha de Dia dos Dais. Após o anúncio que Thammy Miranda - homem trans famoso por ser ator, repórter e filho da cantora Gretchen -, faria parte da campanha, a Natura ganhou novos seguidores nas redes sociais e teve uma alta na sua visibilidade na internet, com crescimento considerável nas buscas no Google, que também se traduziu em alta no valor de suas ações bolsa (FILIPPE, 2020). A despeito das críticas que pode ensejar, a estratégia de marketing teve reflexos positivos.

Isso, no entanto, não significa que essa repercussão positiva seja uma regra. Nesse cenário de apoio de marcas à causa LGBT+, há consumidores que questionam os sentidos veiculados (OLIVEIRA; MACHADO, 2019) a partir do extenso debate sobre pink money, o chamado "dinheiro rosa”, que se refere ao potencial de consumo da comunidade LGBT+. Atualmente, muitas críticas são feitas às empresas que enxergam nessa abordagem apenas uma oportunidade meramente mercadológica.

\section{Discussão metodológica: sobre a observação participante}

A respeito do método escolhido para a realização deste estudo, foram aplicadas, no trabalho de campo, técnicas de inspiração etnográfica, utilizando-se a observação direta para a coleta de dados, com registro em diário de campo. Conforme Geertz (1973) afirma, o que define a etnografia não são as técnicas que podem ser utilizadas, como mapear o campo, manter um diário e transcrever textos. A definição usada por Geertz (1973) aponta para a etnografia como uma descrição densa. Isto envolve tanto uma função interpretativa dos atos observados como a tarefa de encontrar o acesso aos sentidos de vida em cada sociedade. Dessa forma, nossa intenção foi construir um relato do discurso social do grupo em questão disposto em documento que pode ser consultado a qualquer tempo, conservando-se assim o momento e o sentido para estudo (BRAGA, 2008).

A observação participante foi utilizada nesta pesquisa a partir da imersão em diferentes atividades que contaram com a representação de integrantes da ONG Casinha. A observação incluiu a realização de um diário de campo com anotações realizadas após as experiências. Um roteiro de observação participante das atividades também foi usado como instrumento para a pesquisa. Houve pouca intervenção da pesquisadora nesses eventos, sem a influência significativa dela na evolução dos debates, apenas contribuindo com algumas questões e comentários pertinentes à pesquisa.

Foram observados três eventos diferentes, nos quais os gestores da ONG e participantes desempenharam papéis diferenciados. A primeira ocasião foi um debate aberto ao público sobre pink money, organizado pela ONG e com diversos convidados. O segundo momento de observação 
aconteceu em um dos encontros do cineclube da Casinha. E a terceira observação foi feita durante a participação da ONG na Virada Sustentável, um dos maiores eventos sobre sustentabilidade no Brasil. O quadro 3 sintetiza as informações gerais dessas ocasiões.

Quadro 1. Dados gerais dos eventos observados.

\begin{tabular}{|c|l|l|l|}
\hline \multicolumn{1}{|c|}{ Data } & \multicolumn{1}{|c|}{ Evento } & \multicolumn{1}{c|}{ Local } & \multicolumn{1}{c|}{ Horário } \\
\hline 28/06/2019 & Debate: "O tal do pink money" & $\begin{array}{l}\text { Nex Coworking - } \\
\text { Ladeira da Glória }\end{array}$ & $19 \mathrm{~h}$ às 21h30 \\
\hline $15 / 10 / 2019$ & Cine clube: Filme Paraíso perdido & $\begin{array}{l}\text { Nex Coworking - } \\
\text { Ladeira da Glória }\end{array}$ & $\begin{array}{l}18 \mathrm{~h} 30 \text { às } \\
21 \mathrm{~h} 30\end{array}$ \\
\hline 20/10/2019 & Virada sustentável: Aquário LGBT+ & Parque Lage & $15 \mathrm{~h}$ às 16h30 \\
\hline
\end{tabular}

Fonte: elaborado pelas autoras

Os eventos tinham dinâmicas diversas, com diferentes intenções discursivas, o que foi importante para absorver um maior volume de visões e comportamentos. O debate sobre o pink money ocorreu no dia 28 de junho de 2019, como parte da programação proposta para a celebração da semana do orgulho LGBT+. Durante o evento, que recebeu cerca de dez pessoas na plateia, quatro convidados engajados com a comunidade LGBT+ debateram sobre a representatividade na mídia e a atuação das marcas. Os principais pontos abordados foram o quanto as ações das marcas são efetivas e contribuem para a luta. Seriam essas ações só oportunismo? Como pode se contribuir, de fato, com essa causa e tirar a população dessa condição marginalizada?

O evento sobre o pink money ocorreu no Nex Coworking, empresa que oferece espaços compartilhados de trabalho e uma das principais parceiras da ONG. O local, situado na Ladeira da Glória, acolhe diversas atividades da Casinha e recebeu também o segundo evento da observação participante: o cineclube. No dia 15 de outubro de 2019, foi exibido o filme Paraíso Perdido, com a presença de 17 pessoas. A trama se passava em uma casa noturna e apresentava os conflitos, assim como as afetividades, entre personagens LGBT+. Após a exibição, houve um debate sobre a importância de redes, territórios e consumo.

Por fim, o último momento de observação foi na participação da ONG durante a Virada Sustentável. Esse evento, diferente dos outros dois, não era organizo pela ONG, mas sim uma inserção da Casinha em um contexto maior. Seus membros promoveram uma conversa aberta e livre chamada "aquário", com quatro convidados familiarizados com a causa LGBT+ e uma cadeira vazia, onde qualquer um da plateia podia se sentar e contribuir para o debate sobre vivências e estratégias de resistência da comunidade. Não houve uma forte interação do público em geral, mas como era um grande evento com diversas ações espalhadas pelo Parque Lage, muitas pessoas passaram pelo “aquário”, e algumas se sentaram para ouvir o debate. A conversa girou em torno da questão geradora proposta pelos membros da Casinha: como construir uma rede de afeto que integre a diversidade? As posições e opiniões desse debate falaram sobre as oportunidades de inclusão, a relação da comunidade com marcas e as atribuições do Estado.

Após o levantamento dos dados, foi realizada uma análise interpretativa do discurso observado nas diferentes instâncias de 
comunicação acompanhadas, levando-se em consideração que os processos de enunciação em todas essas circunstâncias operaram no interior do contexto sociocultural que os cercavam. O que as pessoas dizem é parte de um sistema complexo de "condições de produção" dos discursos, definido por regras anônimas sempre determinadas por tempos e espaços específicos (FOUCAULT, 1986). Em outra perspectiva, Hine (2015) estabelece a abordagem analítica do discurso como estratégia para desenvolver os insights a partir dos dados coletados, sugerindo olhar em profundidade os enunciados usando técnicas de análise do discurso para examinar os modos de interação entre participantes. Nosso estudo seguiu essa mesma visão para realizar o exame do que nossos interlocutores declararam.

\section{ANÁLISES: REFLEXÕES SOBRE A CIRCULAÇÃO DE SENTIDOS}

Como mencionamos, é possível observar diversas empresas abrindo espaço para a causa LGBT+ nos dias hoje. Vale salientar que, para além das perspectivas de benefício coletivo e de transformação social, as marcas se atraem por números frequentemente divulgados na mídia, a respeito do poder de compra do público LGBT+. Para melhor salientar esse ponto: recente estudo do Google afirma que o potencial financeiro desse segmento no Brasil é estimado em 419 bilhões de reais, o que equivale a 10\% do PIB do país (MARINHO; ENGLERT, 2019). Além disso, já é antiga a notícia de que casais homossexuais brasileiros têm, proporcionalmente, renda média mensal maior que a de casais heterossexuais, segundo dados preliminares sobre rendimentos do Censo 2010 (SANTOS; NALON, 2011). A reflexão aqui não é focada nos aspectos financeiros e de marketing, mas sim na percepção obtida do que foi visto durante os eventos em que se realizou a observação participante.

$\mathrm{O}$ evento sobre pink money, que reuniu diversas pessoas envolvidas com a temática ${ }^{5}$, articulou diversas opiniões sobre o envolvimento das marcas com a população LGBT+; do mesmo modo, os demais eventos também geraram debates interessantes. A fim de facilitar a exposição, seguem agrupadas as principais percepções observadas. As citações diretas das falas não foram aqui identificadas a fim de preservar a identidade dos seus manifestantes ${ }^{6}$ :

\section{Relação de troca}

Um consenso percebido foi que não são interessantes os investimentos sem propósitos consolidados de contribuição para a comunidade LGBT+. "Não é uma questão de demonizar as marcas, mas não queremos só dinheiro. Marcas são marcas e no fim do dia querem lucrar. Mas como podemos usufruir da grana para a causa?”, destacou um dos participantes do debate. Mais do que um espírito de caridade, os argumentos defendiam

5. Mais informações sobre os participantes estão disponíveis no evento no Facebook (NEX COWORKING; CASINHA, 2019). Disponível em: https://bit.ly/3bzoWdd/. Acesso em: 19 jan. 2020.

6. O trabalho de campo fez parte da dissertação mencionada e foi executado em conformidade com as exigências para pesquisa com seres humanos. O parecer positivo do Comitê de Ética em Pesquisa do Centro de Filosofia e Ciências Humanas (CEP-CFCH) da UFRJ tem número 3.408.629 e pode ser consultado na Plataforma Brasil. 
uma relação de troca, com ganhos mais efetivos para pessoas LGBT+. Esse depoimento é muito interessante, pois indica de modo evidente que o interlocutor observado desejava que as marcas produzissem mais do que apenas um discurso publicitário de promoção do culto ao hedonismo. O desejo de troca evidencia a ideia de que a publicidade poderia ser coparceira na divulgação e na aplicação dos princípios de base da causa LGBT, de modo a tornar essa relação efetivamente transformadora. O que de fato se reivindica aqui é a associação aos princípios clássicos da participação política - o engajamento a processos de transformação social que, na tradição, ocorrem através de participação em espaços da democracia representativa, isto é, em partidos políticos, sindicatos e associações de base.

"O grave é a mercantilização das pautas, mesmo tendo um posicionamento político contrário”, mencionaram. Nesse contexto, foi mencionada uma notícia da Forbes (ENNIS, 2019), divulgada na semana anterior, que afirmava que o apoio das marcas à causa LGBT+ muitas vezes era contraditório. Segundo o levantamento realizado, nove das maiores e mais favoráveis corporações LGBT+ dos Estados Unidos destinaram cerca de US\$ 1 milhão ou mais a políticos “antigays” no último período eleitoral. Esses políticos negaram cuidados com a saúde dessa comunidade e não defenderam qualquer legislação em apoio aos direitos LGBT+. Os dados da Forbes, portanto, reafirmam que muitas vezes o discurso de engajamento à causa aparece na superfície, “ surfando” em ondas de tendências, sem profundidade de vínculo com a causa.

Os participantes ressaltaram, sempre em tom firme, a dificuldade de transitar nessa polarização entre o conservadorismo político e a profusão de apoio das marcas. Nesse sentido, eles abordaram a prática do pink washing ${ }^{7}$ e destacaram como é importante o cuidado das marcas para ser um investimento verdadeiro. Afinal, os números de violência e de hostilidade contra as pessoas LGBT+ seguem altos no Brasil, demandando que muitas medidas sejam tomadas.

A partir desse contexto, os gestores da Casinha compartilharam suas experiências. O primeiro financiamento da ONG partiu de 16 empresas, e seus membros afirmam depender do apoio de marcas para o financiamento das atividades da ONG. Ainda assim, eles defendem que as empresas parceiras precisam estar interessadas em ser "mais do que parecer pride”. Isto porque muitas empresas querem exibir que são pró-diversidade, ao passar uma imagem de organização moderna e descontraída para os consumidores. Entretanto, essas mesmas empresas não têm interesse em contratar pessoas LGBT+ e nem em flexibilizar processos de modo a facilitar a inclusão. Em casos assim, os gestores alertam que "mais importante do que vender para esse público, é contratar". Por isso, no diálogo com as marcas, eles argumentam a importância da empregabilidade e oferecem serviços específicos para esse fim. Entre outras ações, a Casinha tem um banco com currículos LGBT+ e oferece gratuitamente auxilia na sensibilização das companhias, oferecendo apoio durante o processo seletivo e buscando promover a empatia no ambiente organizacional. "Para ser realmente friendly tem que apoiar. Tem que ter funcionário, tem que ter publicidade feita por gays. Tem que fazer muito mais do que só pensar na bandeirinha”, eles afirmam.

7. A expressão se refere ao uso da causa LGBT+ exclusivamente para promover uma organização, mascarando os preconceitos e a falta de políticas realmente inclusivas nos "bastidores". 


\section{Foco em pessoas}

No debate sobre a influência das marcas, o foco no cuidado e na atenção para as pessoas LGBT+ se destacaram. Um dos participantes da conversa contou que passou por tempos de sofrimento devido à omissão da sua sexualidade no mundo corporativo e à angústia por receio de julgamento. "Héteros se afirmam o tempo inteiro. Por que gays não podem falar sobre suas relações?”, destacou, salientando que é para essas nuances que as empresas e a sociedade como um todo deveriam estar atentas.

Nesse contexto, foi levantado um questionamento a respeito do retorno financeiro que a população LGBT+ movimenta: por que o consumo desse público é tão exacerbado? Um outro cuidado que os participantes destacaram foi o uso da compra como recurso para compensação da saúde mental. Os gastos podem estar associados a uma forma de compensação do sentimento de inferioridade, assim como ao volume de trabalho que se permitem executar.

Esse olhar atento para a qualidade de vida das pessoas LGBT+ também foi mencionado para avaliar a representação de pessoas gays e trans em campanhas publicitárias, elemento relevante também no contexto das mídias digitais. "É preciso ter atenção com personagens estereotipados e também com perspectivas higienizadas, essa coisa de gay discreto, com passabilidade ${ }^{8}$, que beija na testa”, salientou um dos participantes. Aqui, observa-se uma importante correlação do desejo de autorrepresentação com a autenticidade dos papéis representados. Como observamos, a publicidade contemporânea é perpassada por altas doses de discursos subjetivizantes, de modo que a expressão política seja atravessada e mobilizada pelos corpos dos sujeitos representados nas telas. Nesse sentido, é reivindicada pelos participantes maior autenticidade na escolha de sujeitos do movimento LGBT+ como atores de suas próprias causas.

\section{Implicações da internet}

Durante o debate, dois pontos foram relevantes no âmbito das relações on-line: a insuficiência de visibilidade meramente digital e o rastreamento de ações nos meios on-line.

“Mudar capa no Facebook é muito 2015”. Essa frase foi usada por um dos participantes do debate para alertar que realizar apenas iniciativas de marketing nas mídias sociais é algo ultrapassado. O contexto da fala era a apropriação dos símbolos LGBT+ durante o mês de junho, em que é celebrado o dia do orgulho LGBT+ (28 de junho). Interessante aqui é a associação dessa citação com o debate de Bauman (2008) sobre a representação de causas na superfície na modernidade líquida. Ao adotar causas como um adereço que se usa nos momentos oportunos e se descarta em outros, os sujeitos contemporâneos desenvolveriam um ativismo instantâneo, que não está na base da sua cultura, ou no caso das corporações, na base da cultura organizacional.

Como já mencionamos, muitas marcas buscam transmitir a imagem de empresas modernas ao adotar o discurso LGBT+. Isso, nas mídias sociais, se reflete na inserção de filtros nas imagens de perfil, no compartilhamento de imagens pró-diversidade, entre outras ações. De acordo com a visão predominante no debate, a visibilidade para a causa é um elemento

8. Termo usado como referência para dizer o quanto um membro da comunidade LGBT+ aproxima-se da norma. 
importante para o combate ao preconceito. Entretanto, já tendo passado alguns anos dessa "moda de trocar a capa no Facebook", cabe às marcas a execução de ações mais propositivas, revelando um engajamento mais genuíno com a comunidade LGBT+, como abordado anteriormente.

Outra oportunidade on-line interessante, observada nesse debate foi que "Marca tem biografia. Tem internet para isso". Os participantes sinalizaram que as plataformas da internet podem ser usadas como forma de resgatar o histórico das marcas. Isso pode servir tanto para recuperar posts anteriores e observar o que essas marcas já defenderam, quanto para observar atentamente o que elas divulgam hoje e que ficará registrado para o futuro. Diversas construções on-line simbolizam o registro de memória LGBT+. Mais do que isso, os meios digitais têm a faculdade de rememorar experiências, e seus instrumentos de captura ou de reservatórios ajudam a construir a noção de passado, tanto em termos das nossas vidas privadas, como nos da vivência coletiva (SÁ, 2007; VAN DIJCK, 2007). Isso se aplica também no contexto de atuação das marcas, suas publicações, sites, mídias sociais etc.

\section{CONSIDERAÇÕES FINAIS: PARA ALÉM DO DISCURSO}

Neste artigo, lançamos olhar para a circulação de discursos da comunidade LGBT+ a respeito da aproximação entre marcas e a defesa da diversidade sexual e de gênero. Mais do que avaliar como um engajamento positivo ou negativo, este trabalho buscou, assim como intenta as etnografias, registrar um relato do discurso social de um grupo social formado por representantes da comunidade LGBT+, disposto em documento que pode ser consultado a qualquer tempo.

De uma maneira geral, uma leitura inicial dessa apropriação mercadológica pode considerar tal medida como benéfica em razão dos aspectos relacionados à conquista de visibilidade, inserindo a pauta LGBT+ no cotidiano da sociedade, através dos anúncios comerciais. Muito além dessa visibilidade auferida pelas iniciativas das marcas, as discussões circulantes demonstram especial preocupação com os afetos dos indivíduos representados por tais campanhas e com o modo pelo qual suas relações socioeconômicas podem ser impactadas. Há recorrente reflexão sobre como são retratadas as pessoas e quais mensagens são passadas nas campanhas. Mais do que a representação midiática, se questiona se há correspondência entre o uso da pauta da diversidade em campanhas com iniciativas de empregabilidade por essas organizações. Aprofundamos nossas reflexões com base nas possíveis leituras dos discursos midiáticos e ativistas das marcas.

Em nossas análises sobre os discursos circulantes, observamos como o conceito de ativismos de marcas pode estar regulado na contemporaneidade por reflexões clássicas que estão na base da teoria crítica (ADORNO; HORKHEIMER, 1991), especialmente em suas teses sobre a mercantilização das consciências e a adoção de fórmulas clichês e de soluções midiáticas de superfície para traduzir vínculos de solidariedade mais profundos. Ou ainda, podem estar identificados com as traduções críticas de Baudrillard (1995) e Bauman (2008) sobre a mobilização de subjetividades a partir da lógica das mercadorias. De certo modo, muitas apropriações da causa LGBT+ por marcas se alinham a essa tradição, e disso decorre a emergência do fenômeno crítico do pink money. 
Identificamos, em contrapartida, que as circulações de sentidos das corporações podem ser plurais e heterogêneas e, em certos casos, a adoção da causa pode transcender ao mundo dos simulacros e da retórica publicitária e se articular como princípios ordenadores das filosofias organizacionais, atendendo às demandas por trabalho e renda da comunidade LGBT+. Essa é a proposta, por exemplo, do Fórum de Empresas e Direitos LGBT, organização que reúne instituições em torno da promoção dos direitos LGBT+ e que mobiliza iniciativas nas corporações e diálogos com o público em geral.

Com o olhar mais afinado às proposições de Williams (1958) e Hall (1997), segundo os quais os textos culturais são analisados como produtos de seus contextos, foi possível observar os múltiplos planos de leituras das representações midiáticas. Nesse sentido, identificamos discursos dos nossos interlocutores que salientam ações de corporações mais identificadas com os princípios norteadores das democracias participativas e com os processos de transformação social. Afinar o olhar para observar as nuances e diferenças de posicionamentos das organizações parece ter sido o tom de mobilização do primeiro evento observado: o debate " $\mathrm{O}$ tal pink money".

A observação participante dos eventos nos fez refletir também sobre os valores que emergem das narrativas dos ativismos de marcas: as retóricas que apostam na valorização dos indivíduos, na liberdade de escolha como o motor do ativismo e no atravessamento pelas políticas de reconhecimento e pelos códigos de valorização dos corpos e subjetividades mobilizadas (MACHADO, 2011; TAYLOR, 1992).

O que se espera é que essa afirmação da diversidade, independentemente de sua origem, consiga sustentar um novo contexto social em que haja o reconhecimento de gêneros, subjetividades e sexualidades não normativas. O bem-estar coletivo na coexistência humana não pode existir sem resguardar a pluralidade desses percursos.

\section{REFERÊNCIAS}

ADORNO, Theodor; HORKHEIMER, Max. Dialética do Esclarecimento: fragmentos filosóficos. 3. ed. Rio de Janeiro: Zahar, 1991.

BAUDRILLARD, Jean. A sociedade de consumo. Rio de Janeiro: Elfos, 1995.

BAUMAN, Zygmunt. Vida para o consumo: a transformação das pessoas em mercadorias. Rio de Janeiro: Zahar, 2008.

BLEE, Kathleen M.; CREASAP Kimberly A. Conservative and Right-Wing movements. Annual Review of Sociology, Pittsburgh, v. 36, p. 269-286, 2010.

BRAGA, Adriana. Personas materno eletrônicas: feminilidade e interação no blog Mothern. Porto Alegre: Sulina, 2008

DOUGLAS, Mary; ISHERWOOD, Baron. O mundo dos bens: para uma antropologia do consumo. Rio de Janeiro: Editora da UFRJ, 2004.

ENNIS, Dawn. 9 corporações que usam as cores LGBTQ+, mas doaram milhões a projetos antigay. Forbes Brasil, São Paulo, 24 jun. 2019. Disponível em: https://bit.ly/3oogAKC. Acesso em: 22 jan. 2020.

FACCHINI, Regina; FRANÇA, Isadora Lins. De cores e matizes: sujeitos, conexões e desafios no Movimento LGBT brasileiro. Sexualidad, Salud y Sociedad, Rio de Janeiro, n. 3, p. 54-81, 2009

FILIPPE, Marina. Thammy Miranda em campanha de Dia dos Pais: o que a Natura ganha com isso? Exame, São Paulo, 29 jul. 2020. Disponível em: https://bit.ly/2RtkndD. Acesso em: 30 jul. 2020. 
FÓRUM DE EMPRESAS E DIREITOS LGBTI+. Empresas. [S. I.]: Fórum de Empresas e Direitos LGBTI+, 2016. Disponível em: https://bit.ly/3wgh9c7. Acesso em: 30 jul. 2020.

FRANÇA, Isadora Lins. Consumindo lugares, consumindo nos lugares: homossexualidade, consumo e subjetividades na cidade de São Paulo. Rio de Janeiro: Editora da Uerj, 2012.

GEERTZ, Clifford. A interpretação das Culturas. Rio de Janeiro: Zahar, 1973.

Gay \& Lesbian Alliance Against Defamation - GLAAD. Accelerating Acceptance 2018. Los Angeles: GLAAD, 2018. Disponivel em: https://bit.ly/3wbs8DH. Acesso em: 30 jul. 2020.

GRUPO GAY DA BAHIA. Mortes violentas de LGBT+ no Brasil: relatório 2018. Salvador: Grupo Gay da Bahia, 2018. Disponível em: https://bit.ly/3fEEyOz. Acesso em:13 fev. 2018.

HALL, Stuart. Encoding/decoding. In: DURING, S. (ed.) The cultural studies reader. 4. ed. London: Routledge, 1997. p. 90-103.

HINE, Christine. Observing and experiencing online/offline connections. In: HINE, C. Ethnography for the Internet: embedded, embodied and everyday. London: Bloomsbury Academic, 2015. p. 89-123.

MACHADO, Mônica. Consumo e Politização: discursos publicitários e novos engajamentos juvenis. Rio de Janeiro: Mauad: Faperj, 2011.

MARCUSE, Herbert. One-dimensional man: studies in the ideology of advanced industrial society. Boston: Beacon Press, 1992.

MARINHO, Maria Helena; ENGLERT, Paula. Por que sua marca deveria saber o que a comunidade LGBTQIA+ espera dela. Think with Google, São Paulo, 26 out. 2019. Disponível em: https://bit.ly/3wf84Ah. Acesso em: 19 jan. 2020.

NEX COWORKING; CASINHA. O tal do Pink Money. Rio de Janeiro, 28 jun. 2019. Facebook: nexcoworking: casinhaacolhida. Disponível em: https://bit.ly/3bzoWdd/. Acesso em: 19 jan. 2020.

NUNAN, Adriana. Homossexualidade: do preconceito aos padrões de consumo. Rio de Janeiro: Caravansarai, 2003.

OLIVEIRA, Arize Souza Fernandes de. Lugares do arco-íris: um olhar para comunidade LGBT+ a partir da Antropologia Digital. 2020. Dissertação (Mestrado em Psicossociologia de Comunidades e Ecologia Social) - Universidade Federal do Rio de Janeiro, Rio de Janeiro, 2020.

OLIVEIRA, Arize Souza Fernandes de; MACHADO, Mônica. Mídias digitais e reações negativas às campanhas publicitárias LGBT. Consumer Behavior Review, Recife, v. 3, p. 14-23, 2019.

SÁ, Alberto. A Web 2.0 e a Meta-Memória. In: Congresso da Associação Portuguesa de Ciências da Comunicação, 5., 2007, Braga. Anais [...]. Braga: Centro de Estudos de Comunicação e Sociedade da Universidade do Minho, 2007. p. 1426-1435.

SALES, Ricardo Gonçalves de. Diversidade no trabalho: valores organizacionais e adesão a normas em organizações participantes do fórum Empresas e Direitos LGBT. In: Congresso Internacional Comunicação e Consumo, 5., 2015, São Paulo. Anais [...]. São Paulo: Faculdade Casper Líbero, 2015.

SANTOS, Débora; NALON, Tai. Casais gays ganham mais que casais heterossexuais, mostra IBGE. G1, Brasília, DF, 16 nov. 2011. Disponível em: https://glo.bo/3w6EcpQ. Acesso em: 21 jan. 2019.

SPARGO, Tamsin. Foucault e a teoria queer: seguido de Ágape e êxtase: orientações pós-seculares. Tradução de Heci Regina Candiani. Belo Horizonte: Autêntica, 2017.

TAYLOR, Charles. Ethics of authenticity. Cambridge, MT: Harvard University Press, 1992.

VAN DIJCK, José. Mediated memories in the digital age. Palo Alto: Stanford University Press, 2007.

WILLIAMS, Raymond. Culture and society. London: Penguin, 1985. 